TẠP CHÍ KHOA HỌC ĐẠI HỌC TÂN TRÀO

ISSN: 2354 - 1431

http://tckh.daihoctantrao.edu.vn/

\title{
MỘT VÀI ĐỀ XUẤT VỀ VIỆC KHAI THÁC MA THUẬT DÂN GIAN TRONG HOẠT ĐỘNG DU LỊCH
}

\author{
Nguyễn Thị Suối Linh ${ }^{a *}$ \\ ${ }^{a}$ Truòng Đại học Khoa học, ĐH Thái Nguyên \\ *Email: linhnts@tnus.edu.vn
}

\section{Thông tin bài viết}

Ngày nhận bài:

28/4/2020

Ngày duyệt đăng:

10/6/2020

Tù khóa:

Ma thuật, du lịch, hướng dẫn viên, tín ngữ̃ng, huyền bí

\begin{abstract}
Tóm tắt
Trên cơ sở tìm hiểu về ma thuật trong đời sống dân gian các tộc người ở Việt Nam, bài báo đưa ra một số đề xuất nhằm khai thác hình thức tín ngưỡng này trong hoạt động du lịch. Theo đó, tri thức về ma thuật là nguồn tư liệu hướng dẫn phong phú, hấp dẫn. Nó còn giúp hướng dẫn viên và du khách có ứng xử phù hợp với văn hóa bản địa. Như một đặc trưng đời sống tâm linh cộng đồng, ma thuật có thể được ứng dụng để tạo ra không gian trưng bày ấn tượng hay sản phẩm du lịch độc đáo, bao gồm: hoạt động trải nghiệm nghi thức tín ngưỡng dân gian, sản phẩm lưu liệm gắn với ma thuật, tham quan bảo tàng ma thuật...
\end{abstract}

\section{1. Đặt vấn đề}

Văn hóa bản địa nói chung, tín ngưỡng, phong tục tập quán nói riêng luôn được coi là một nguồn tài nguyên du lịch, đặc biệt là du lịch văn hóa - cộng đồng, gắn với phát triển bền vững. Nghiên cứu về ma thuật dân gian, tác giả nhận thấy, hệ thống tri thức, kinh nghiệm bản địa này hoàn toàn có thể khai thác trong lĩnh vực du lịch ở nhiều khía cạnh: vừa là tư liệu trong hoạt động hướng dẫn lữ hành, vừa là “vỉa quặng” để triển khai những sản phẩm du lịch đặc thù, gắn với những khu vực đa dạng văn hóa.

\section{Nội dung nghiên cứu}

\subsection{Khái quát về ma thuật dân gian}

Thuộc phạm trù nghiên cứu của nhiều lĩnh vực khoa học, ma thuật (tương ứng với các thuật ngữ magic, witchcraft, voodoo trong tiếng Anh, Mĩ; maura trong tiếng Nga, mageia trong tiếng Hy Lạp) thu hút sự quan tâm của nhiều nhà khoa học thuộc các chuyên ngành khác nhau như tôn giáo học, dân tộc học, văn hóa học... Vấn đề định nghĩa, nhận diện, xây dựng và phiên dịch thuật ngữ ma thuật đầy phức tạp, với những quan điểm khác nhau gây ra cuộc tranh luận kéo dài hơn một thế kỷ với sự tham gia của những nhà nhân học kinh điển. Có thể hiểu một cách đơn giản, ma thuật là hình thức sinh hoạt tín ngưỡng kỳ bí thường được thực hiện bằng sự kết hợp giữa lời nói, động tác và vật thiêng để tác động đến bản thân và thế giới nhằm đạt được kết quả mong muốn.

Trong lòng văn hóa dân gian, sự tồn tại của ma thuật rất da dạng. Tiếp thu quan điểm khoa học của các nhà nghiên cứu, chúng tôi đưa ra hệ thống phân loại phương thuật dân gian như sau:

- Xét theo phạm vi, muc đích sủ dụng có: ma thuật điều khiển tự nhiên khí hậu; ma thuật trong sản xuất, ma thuật trong đời sống sinh hoạt cá nhân (bảo vệ sức khỏe, giải quyết tai nạn bất ngờ, điều khiển tình cảm); ma thuật trong đời sống xã hội (giải tỏa mâu thuẫn cộng đồng, cầu an cho làng bản).

- Xét theo phương thức tác động có: ma thuật thực hiện bằng hành vi (như ăn trộm, làm lén, nín thở, phù, gõ...), ma thuật thực hiện bằng ngôn ngữ (lời chú, các câu nói phép...), ma thuật thực hiện bằng công cụ (con dao, cái kim, lá bùa, củ tỏi...). Ở nhiều trường hợp, một phương thuật được làm nên bởi sự tác động đồng thời của cả hành vi, ngôn ngữ và vật làm phép. 
- Xét theo đối tương thi hành có: ma thuật đặc biệt do pháp sư, đạo sĩ thực hiện và ma thuật phổ biến mà người thường cũng có thể thực hiện (hoặc thông qua những người có đặc điểm riêng như góa chồng, khác họ, dễ sinh, có tật...).

- Xét theo tần suất sử dụng có: ma thuật sử dụng như một quy trình trong sản xuất, phong tục (gánh nước đầu năm, mừng tuổi, trấn trạch nhà mới, giã cối đón dâu, nghi thức làm phép khi cấy trồng, thu hoạch, chăn nuôi gia súc, gia cầm...) và ma thuật mang tính chất tình huống (chữa bệnh, xử lý tai nạn bất ngờ, trợ sinh, bắt sâu, chữa sâu róm đốt, bắt ròi cho gia súc...).

- Xét theo tiêu chuẩn đạo đức có ma thuật bảo vệ, cứu trợ và các ma thuật làm hại. Thuật ngữ tôn giáo thế giới gọi đó là ma thuật đen (làm hại) và ma thuật trắng (có lợi). Tuy nhiên, giống như quan điểm của GS. Phan Hữu Dật, tác giả cho rằng sự phân loại này chỉ mang tính tương đối bởi nhiều khi, để giúp ích cho đối tượng này phải gây hại đối tượng khác.

Từ quá khứ đến hiện tại, từ phương Đông đến phương Tây, từ các dân tộc thiểu số với đời sống tâm linh phong phú đến cộng đồng cư dân đô thị, ta vẫn thấy sự hiện diện của ma thuật trong rất nhiều lĩnh vực của đời sống vật chất và tinh thần, sinh kế và tín ngưỡng. Ma thuật xuất hiện, khi con người muốn điều chỉnh thời tiết, khí hậu, phục vụ cho sản xuất, cầu bình an cho mỗi nếp nhà. Ma thuật phát huy vai trò trong mỗi thao tác của chu trình trồng trọt, chăn nuôi, như thuật giữ giống, gieo mạ, trồng ngô, diệt trừ chuột bọ, chăm cho lợn mau lớn, gà đẻ sai, bò dê chăn thả không bị lạc đàn... Đặc biệt, mẹo thuật phát huy hiệu quả, ít nhất là trên bình diện tâm lý, trong quá trình bảo vệ sức khỏe con người, nhất là những đối tượng nhạy cảm như sản phụ và trẻ sơ sinh. Nghiên cứu về ma thuật trong bối cảnh giao lưu văn hóa và phát triển kinh tế - kĩ thuật tạo sở để bảo lưu kinh nghiệm quý trong dân gian, ứng dụng văn hóa dân gian vào đời sống. Mặt khác, dựa trên các minh chứng khoa học, người nghiên cứu có thể khẳng định tính phi lý, nguy hại của nhiều ma thuật lạc hậu làm ảnh hưởng đến sức khỏe, kinh tế, đời sống con người.

2.2. Úng dụng, khai thác tri thức ma thuật dân gian trong hoạt động du lịch
2.2.1. Sử dụng tri thức ma thuật dân gian làm nguồn tư liệu văn hóa trong hoạt động hướng dẫn, lũ hành

- Tu liệu huoóng dẫn cung đường

Du lịch không phải chỉ là điểm đến, mà là cả một cuộc hành trình từ khi du khách rời khỏi ngôi nhà của họ. Vì vậy, tác nghiệp trên cung đường là nhiệm vụ quan trọng của hướng dẫn viên, giúp chuyến đi thêm giá trị, giảm bớt mệt mỏi cho du khách trên những chặng đường dài. Thực tế, nhiều hướng dẫn thường lựa chọn phương pháp hoạt náo (hát, kể chuyện cười, chơi trò chơi...), điều này đem đến không khí sôi động nhưng là một sự lãng phí những tài nguyên quý giá trên hành trình đi qua những sắc thái thiên nhiên và văn hóa sinh động. Tri thức về phương thuật dân gian, có thể làm tài liệu thuyết minh cung đường với những mục đích, nội dung sau:

+ Trấn an tâm lý: Trong tâm lý của nhiều người, du lịch vùng dân tộc thiểu số mặc dù hấp dẫn song có chút “đáng ngại” bởi những phong tục văn hóa bí ẩn giữa vùng "thâm sơn cùng cốc", giữa vương quốc của bùa ngải, ma gà. Không ít người Kinh miền xuôi có định kiến, rằng người dân tộc thiểu số ai cũng giỏi chài, nèm và các phương thuật làm hại. Điều này có thể khiến chuyến trải nghiệm bớt phần thú vị. Nhiều trường hợp, khách thể hiện thái độ đề phòng, nghi kỵ một cách thái quá và thiếu tế nhị, gây tổn thương cho cộng đồng bản địa. Vì thế, trên đường đi, hướng dẫn viên nên cung cấp thông tin về ma thuật dân gian, lý giải về bản chất của bùa chú, nèm chài, huyết ngải, thư phù... giúp du khách có cái nhìn khách quan, cởi mở với văn hóa vùng cao, bớt đi những định kiến thiếu căn cứ.

+ Định huoóng úng xư: Bên cạnh việc trấn an du khách, rằng đa phần các ma thuật, bùa chú đều hướng đến mục đích bảo vệ, hướng dẫn viên cũng có thể nghiên cứu tài liệu, tham khảo ý kiến của những người có hiểu biết về văn hóa để đưa ra lời khuyên phù hợp về dấu hiệu nhận biết, cách phòng tránh những ma thuật làm hại khi đến một vùng đất lạ (như không vứt tóc rụng bừa bãi, tránh để quên tư trang cá nhân, bảo vệ các thông tin riêng tư như ngày sinh, địa chỉ, đi đường bắt gặp vật lạ không nên tò mò cầm nắm, nghe tiếng gọi, lời nói "bất thường" không vội vàng đáp lời...). Khi qua những địa phương được coi là "vùng lõi” của ma thuật, điều hành tour và hướng dẫn nên tránh dừng xe 
ăn uống hoặc chủ động nhắc nhở du khách. Bên cạnh đó, bản thân hướng dẫn viên và du khách cần có những hiểu biết cơ bản để điều chỉnh cách ứng xử phù hợp theo nguyên tắc tôn trọng tín ngưỡng của người bản địa. Ví dụ, hầu hết các tộc người đều có kiêng kị nhất định đối với phụ nữ có thai. Do vậy, nếu đoàn khách có người mang thai cần lưu ý và thông cảm cho gia đình nếu phải áp dụng một số ma thuật dân gian để giải trừ rủi ro (chẳng hạn, theo quan niệm của người Mông, thai phụ đến thăm bà đẻ sẽ dẫm cạn mạch sữa, phải làm mẹo bằng cách lấy giày dép rửa sạch đặt vào gầm giường trẻ nhỏ).

+ Lồng ghép thuyết minh về các địa chí, danh nhân: Trên cung đường, rất nhiều địa danh gắn với huyền thoại, dã sử mang yếu tố bí thuật dân gian. Hướng dẫn viên có thể tạo ra những bài thuyết minh ấn tượng bởi yếu tố bí ẩn ma thuật luôn luôn hấp dẫn, ví dụ như huyền thoại vùng Thất Khê (Lạng Sơn) mà tác giả sưu tầm được qua lời kể của ông Nguyễn Xuân Bách (giảng viên trường CĐ Văn hóa nghệ thuật Việt Bắc - Thái Nguyên): "Ngày xưa, ở Thất Khê có nhiều người Hoa sinh sống, làm ăn phát đạt, tích trữ được nhiều của cải, vàng bạc. Sẵn có phép phong thủy và trấn yểm nên họ thường đem vàng bạc đi chôn tại những nơi địa linh. Đồn rằng, trên đỉnh núi chếch hướng Đông Bắc cánh đồng Thất Khê một kho báu, nơi người ta đã chôn sống 99 bà chửa để tế thần. Câu chuyện đáng sợ đi vào quên lãng cho đến một ngày nọ, có tốp người Hoa kéo nhau lên núi. Họ cúng bái một ngày trên ấy rồi quây cót kín mít xung quanh. Sáng hôm sau, người dân đi qua thấy khu ấy bị đào xới, trêm nền đất, có nhiều vòng tròn to nhỏ, đồn là vết đáy chum, đáy chĩnh đựng vàng. Tại cái chỗ bàn đặt hương án, người ta thấy trên cái đĩa dâng tế phẩm có 99 cái đòng lúa non và một con cá chép đang chửa”.

Rất nhiều địa phương còn lưu truyền những huyền thoại ma thuật kỳ bí như thế. Đây là nguồn tư liệu để hướng dẫn viên lồng vào các bài thuyết minh, tạo hấp dẫn trên hành trình khám phá văn hóa cung đường.

\section{- Tu liệu thuyết minh tại điểm}

Kiến thức về ma thuật dân gian là một bộ phận trong hệ thống tri thức tổng quan về điểm đến, trong mối quan hệ tổng hòa của đặc điểm sinh thái, hoạt động sản xuất, đời sống vật chất và tinh thần:

+ Trong quá trình du khách khám phá hoạt động sản xuất nông nghiệp và nghề thủ công, hướng dẫn viên tại điểm có thể giới thiệu về những ma thuật dự đoán, điều khiển thời tiết, ma thuật nông nghiệp (gieo hạt, gặt hái, phòng chuột bọ, sâu bệnh, chăm nuôi gia súc gia cầm), các kiêng kị và ma thuật hóa giải vi phạm kiêng kị trong sản xuất và sinh hoạt;

+ Thuyết minh về kiến trúc nhà ở, ẩm thực, trang phục kèm phần lý giải ý nghĩa của những chi tiết, vật dụng mang dấu ấn ma thuật như bùa, taleo, bồ vía, bó lúa, ống bương làm phép, hòn đá kê chân kiềng, cột cái nhà sàn...;

+ Giới thiệu về các nghi lễ ma thuật hoặc một nghi thức ma thuật cụ thể trong lễ hội địa phương;

+ Đan xen với hoạt động thuyết minh, hướng dẫn viên có thể giao lưu, chia sẻ với khách về những đề tài gần gũi trong cuộc sống, gắn với ma thuật. Ví dụ, người Khơ-mú có thuật trồng khoai sọ, bí đỏ xen lúa, ngô trên nương. Khi thu hái bà chủ phải cố tình để chúng chạm vào nhau cho "linh tinh giao hòa", lúa ngô các vụ sau dễ dàng sinh sôi nảy nở. Phong tục này gợi ra nhớ đến những kinh nghiệm trồng cấy ruộng nước đậm chất phồn thực của người miền xuôi và mở ra một đề tài thảo luận thú vị cho du khách. Một số mẹo chữa bệnh, chăm sóc phụ nữ có thai, sản phụ và trở sơ sinh là sự kết hợp giữa yếu tố tín ngưỡng và bài thuốc, kinh nghiệm dân gian có tính khoa học. Trong quan niệm nhiều người, miền núi là một thế giới bí ẩn với vô vàn kinh nghiệm quý giá có thể tiếp thu, học hỏi. Đối tượng khách du lịch là nữ giới và người cao tuổi có xu hướng quan tâm đến vấn đề này.

2.2.2. Khai thác trong hoạt động trung bày, tái hiện,

\section{tổ chúc trải nghiệm}

Quá trình xây dựng, phát triển điểm du lịch luôn cần đến sự góp ý của cộng đồng và các nhà khoa học về định hướng khai thác tài nguyên văn hóa bản địa trong thiết kế không gian, kiến trúc, xây dựng sản phẩm du lịch theo hướng vừa đáp ứng nhu cầu, thị hiếu du khách, vừa tôn trọng và phát huy các giá trị văn hóa cộng đồng. Ma thuật dân gian hoàn toàn có thể được xem là một nguồn tài nguyên nhân văn khai thác dưới nhiều góc độ:

- Hoàn thiện hệ thống kiến trúc nhà ở truyền thống với dấu ấn tín ngưỡng dân gian;

- Xây dựng nhà hàng, khu nghỉ dưỡng, khu vui chơi giải trí, địa điểm check-in có sử dụng chất liệu văn hóa dân gian gắn với ma thuật như lá bùa, sợi dây vía, chiếc địu, các công cụ lao động đính giấy đỏ, bồ vía, taleo, túm lông động vật...;

- Xây dựng dịch vụ dưỡng sinh, chăm sóc sức khỏe có sự kết hợp của y thuật dân tộc và mẹo chữa bệnh dân gian; 
- Thiết kế đồ lưu niệm đặc trưng gắn với ma thuật như các vật dụng cầu may, trừ tà ...;

- Tổ chức các hoạt động trải nghiệm độc đáo: Khách tham quan không chỉ được quan sát, giới thiệu những dấu tích, hiện vật gắn với ma thuật dân gian mà còn được trải nghiệm những hoạt động văn hóa tín ngưỡng thực tiễn, ví dụ:

+ Trải nghiệm khâu địu, làm vòng vía, vòng dâu, túi bùa, quả còn, mũ trẻ em: Vào những ngày đặc biệt, khách có thể thỉnh xin thầy cúng những lá bùa bảo vệ sức khỏe và trải nghiệm hoạt động khâu túi bùa theo sự hướng dẫn của người có kinh nghiệm. Tuy nhiên, cần lưu ý rằng, có những phương thuật ở một thời điểm nhất định là rất tốt song sẽ gây phương hại trong tình huống khác. Ví dụ, theo tư liệu của Hoàng Anh Sướng, thầy mo người Mường có thể làm bùa gắn bó từ hai mảnh áo, đôi đũa đang ăn dở của đôi vợ chồng. Nhưng khi một trong hai người mất, theo tín ngưỡng, người kia cũng sẽ phải “đi theo”. Để giải bùa, cần phép cao tay hơn để tách hai đôi đũa hoặc lấy hai mảnh vải áo (được cất giữ), đem ra suối, khấn đọc thần chú, thả chúng trôi về hai hướng khác nhau [6]. Trường hợp thầy Mo đã mất hoặc thất lạc mà không thể giải bùa, sẽ gây nguy hiểm hay tâm lý lo lắng, bất an cho người còn lại. Vì thế, tất cả việc khai thác du lịch tâm linh, cần vô cùng thận trọng.

+ Trải nghiệm trò chơi dân gian mang tính ma thuật: ở một số cộng đồng, vẫn lưu truyền những trò chơi dân gian mang tính ma thuật kỳ bí như trò đồng ếch, đồng chổi, đưa ma, bói chén (người Kinh), đẩy gậy, nhảy lửa (Pà Thẻn, Dao)... Những trò chơi này có thể lồng ghép vào các hoạt động vui chơi ban đêm, trong không gian tạo cảm giác linh thiêng, bí ẩn (như cắm trại trong rừng, nhà sàn), đem đến cho du khách những trải nghiệm ấn tượng.

\subsubsection{Xây dụng tour du lịch trải nghiệm chuyên}

\section{biệt}

Là một quốc gia nông nghiệp, người Việt Nam tin vào thế giới tâm linh và có đời sống tín ngưỡng phong phú. Bên cạnh hình thức du lịch tâm linh phổ biến như thăm viếng đền, chùa, lễ hội, có thể xây dựng các tour chuyên biệt chủ đề trải nghiệm ma thuật dân gian như: khám phá những vùng đất kỳ bí nổi tiếng thuật bùa ngải nơi du khách có thể gặp gỡ người thực, việc thực; khám phá ma thuật nông nghiệp qua lễ xuống đồng, mừng lúa mới, cầu mưa, trừ dịch bệnh; khám phá y thuật dân gian gắn với tín ngưỡng... Ở đây, chúng tôi minh họa cụ thể hơn với tour du lịch tâm linh mang chủ đề: "Khám phá ma thuật dân gian trong Tết Đoan Ngọ của người Việt”.
Trong cuốn "Hội hè lễ tết của nguời Việt”[5], nhà dân tộc học Nguyễn Văn Huyên khẳng định, "tết Đoan Ngọ là lễ kỳ lạ nhất trong lịch sử người Việt” bởi nó là một chuỗi những ma thuật độc đáo: Tắm bằng nước đun rễ cây thơm, hoặc hoa nhài để xua tà khí. Phơi sách vở, đồ đạc để sự học hành, làm ăn được sáng loáng, khai thông. Nếu trời mưa đúng giờ ngọ, thì lấy ống tre hứng nước mưa, coi nước đó có tác dụng thần diệu, có thể chữa bệnh đau mắt, đau bụng. Để xua đuổi tà ma, lấy lá ngải tết hình con giáp của năm và treo vào cửa nhà, với niềm tin mùi hắc của lá ngải sẽ góp phần giúp con giáp có thêm sức mạnh, che chở cho dân chúng tà ma, chướng khí. Phụ nữ sẽ thắt chặt bụng bằng "dây vôi”, sau một thời gian, họ sẽ cởi dây ra, buộc vào cột nhà và nói: "Bệnh làm thân tôi đau quặn hãy nhập vào cây cột này”. Trẻ con được đeo vào cổ những chiếc bùa làm bằng chỉ ngũ sắc, trong đựng bột nhang hay bột thần sa, chanh, hạt lựu, cà, phật thủ... Các bà mẹ còn mang những chiếc áo của con tới đền, nhờ đóng vào đó dấu đỏ của các vị thần hùng mạnh. Trên cơ sở những tri thức dân gian về phương thuật trong ngày tết Đoan Ngọ, có thể xây dựng một số sản phẩm du lịch sau:

- Tham quan làng quê, trải nghiệm không gian chợ truyền thống ngày tết Đoan Ngọ.

- Trải nghiệm làm các món bánh dân gian tế tổ tiên và thần Hoàng trùng (theo phong tục ở một số địa phương).

- Theo người bản địa đi tìm các cây thuốc quý, cắt và phơi thuốc, làm điếu ngải, tìm hiểu về thuốc nam và y học dân tộc.

- Xin bùa và trải nghiệm làm bùa (những loại bùa đơn giản, làm từ các loại thảo dược), tết con giáp bằng lá ngải, khâu túi bùa.

- Trải nghiệm một số phương thuật dân gian như nhuộm móng, thắt bụng, khảo quả.

- Dưỡng sinh bằng các liệu pháp dân gian.

- Tham gia trồng cây thuốc...

\subsubsection{Xây dụng bảo tàng chủ đề ma thuật}

Bảo tàng là công trình kiến trúc có giá trị lưu giữ văn hóa, lịch sử, đánh dấu từng chặng đường trên hành trình văn minh nhân loại. Bảo tàng được xem như một trong những điểm đến hấp dẫn, là sự lựa chọn của những du khách yêu văn hóa. Chúng tôi đưa ra ý tưởng xây dựng bảo tàng với chủ đề ma thuật bởi: Thứ nhất, đất nước ta có thế mạnh về văn hóa tâm linh; các hình thức ma thuật dân gian đa dạng, kỳ bí; nguồn tư liệu văn bản cũng vô 
cùng phong phú. Thứ hai, du khách có xu hướng thích khám phá, trải nghiệm, chụp ảnh tại những không gian mới mẻ, lạ lẫm, kỳ bí. Thứ ba, hiện tại, trên cả nước, chưa có công trình bảo tàng nào khai thác chủ đề đặc biệt này.

Kết cấu bảo tàng Ma thuật bao gồm nhiều không gian như: ma thuật phương Đông, ma thuật phương Tây, ma thuật châu Phi - Mĩ La Tinh... Trong mỗi không gian có thể khai thác các hình tượng như thầy phù thủy, các hiện vật ma thuật, tái hiện nghi lễ ma thuật. Ngoài ra, có không gian trải nghiệm, phòng dịch vụ, phòng trưng bày tác phẩm nghệ thuật về đề tài ma thuật, phòng chụp ảnh...

\section{Kết luận}

Mặc dù được coi là một trong những hình thức tôn giáo cổ đại nhất trong lịch sử, song ma thuật vẫn tồn tại đến ngày nay, bất chấp sự phát triển mạnh mẽ của khoa học duy lí. Ngoài ý nghĩa về mặt tâm linh đối với cộng đồng cư dân bản địa, các tri thức ma thuật có thể được khai thác như một nguồn tài nguyên du lịch dồi dào tạo ra nhiều sản phẩm độc đáo. Tuy nhiên, việc làm này đòi hỏi sự cẩn trọng và những định hướng khai thác hợp lý trên cơ sở tôn trọng văn hóa truyền thống. Chúng tôi hy vọng có thể cụ thể hóa những ý tưởng trên đây với những kết quả thực nghiệm cụ thể, ở bước tiếp theo của nghiên cứu

\section{TÀI LIỆU THAM KHẢO}

[1]. Trần Thúy Anh (chủ biên, 2014), Giáo trình du lịch văn hóa - Nhũng vấn đề lí luận và nghiệp vu, $\mathrm{Nxb}$ Giáo dục, Hà Nội.

[2]. Phan Hữu Dật (2009), "Ma thuật làm hại trong tín ngưỡng các dân tộc’", Tạp chí Dân tộc học, số 7, tr.1519.

[3]. Đỗ Thị Thu Hà (2019), "Ma thuật - Khoa học tôn giáo: một thế kỷ tranh luận của nhân học phương Tây và vấn đề về sự phiên dịch tương đồng", Tạp chí Nghiên cứu văn hóa Việt Nam, số 3(183).

[4]. Nguyễn Thị Hiền (2014), "Ma thuật - nhận diện và nghiên cứu trong nhân học", Tạp chí Nghiên cứu tôn giáo, số 9 .

[5]. Nguyễn Văn Huyên (2017), Hội hè lễ tết của nguời Việt, Nxb Thế giới, Hà Nội.

[6]. Lê Văn Kỳ, Thu Loan (2012), Lễ hội nông nghiệp Việt Nam, Nxb Văn hóa Dân tộc, Hà Nội.

[7]. Hoàng Anh Sướng (2016), Bùa ngải xú Mường, Nxb Công an nhân dân, Hà Nội. 


\section{Some suggestions to expoit folk magic for tourism}

Nguyen Thi Suoi Linh

Article info

Recieved:

28/4/2020

Accepted:

10/6/2020

Keywords:

Magic, tourism, guides,

belief, mysterious

\begin{abstract}
Based on the research on folk magic of ethnic groups in Vietnam, the article offered some suggestions to exploit magic in tourism activities. Accordingly, the knowledge of magic is a rich, interesting guide resource. It also helps guides and visitors learn how to behave like local culture. Magical images and objects can be displayed in museums or used for decoration. Especially, it could become a unique travel product.
\end{abstract}

